\title{
Behavior and productivity of cows milked in automated systems before diagnosis of health disorders in early lactation
}

\author{
M. T. M. King, ${ }^{*}$ S. J. LeBlanc, $†$ E. A. Pajor,ł T. C. Wright,§ and T. J. DeVries*1 \\ *Department of Animal Biosciences, and \\ †Department of Population Medicine, University of Guelph, Guelph, ON, N1G 2W1, Canada \\ $\ddagger$ Faculty of Veterinary Medicine, University of Calgary, Calgary, AB, T2N 1N4, Canada \\ §Ontario Ministry of Agriculture, Food and Rural Affairs, Guelph, ON, N1G 4Y2, Canada
}

\begin{abstract}
Associations of electronically recorded data were examined before diagnosis of health disorders in earlylactation cows in herds with automated milking systems (AMS). Rumination time, activity, and milk yield data were collected for 8 mo for 605 early-lactation cows in 9 commercial AMS herds. Using multivariable generalized linear regression models controlling for parity and days in milk, data were examined relative to the day of diagnosis for health disorders occurring in absence of, or at least $14 \mathrm{~d}$ before, another disorder: mastitis $(\mathrm{n}=$ $13)$, new cases of lameness $(\mathrm{n}=45)$, subclinical ketosis (SCK; $\mathrm{n}=113)$, and purulent vaginal discharge $(\mathrm{n}=$ 49). All cases of displaced abomasum $(\mathrm{DA} ; \mathrm{n}=8)$ occurred in conjunction with other disorders. Deviations from baseline among affected cows were examined, as well as differences compared with a group of healthy cows and an average group of all cows, who were given mock diagnosis days using the mean days in milk at diagnosis for each disorder. On 6 to $14 \mathrm{~d}$ of the $2 \mathrm{wk}$ before diagnosis, cows with DA or mastitis had lower milk yield, rumination time, milking frequency, activity, and milk temperature compared with healthy cows as well as deviations from their own baseline rumination time and milk data starting 4 to $12 \mathrm{~d}$ before diagnosis. Cows with DA had lower AMS supplement intake than healthy cows and deviations from their baseline activity and milk temperature starting 6 and $4 \mathrm{~d}$ before diagnosis, respectively. Cows with mastitis had greater milk conductivity than healthy cows and deviated from their baseline milking frequency and conductivity 8 and $12 \mathrm{~d}$ before diagnosis, respectively. Compared with healthy cows, those with SCK or new cases of lameness generally had lower milk yield, rumination time, milk tem-
\end{abstract}

Received August 14, 2017.

Accepted December 21, 2017.

${ }^{1}$ Corresponding author: tdevries@uoguelph.ca perature, supplement intake, and milking and refusal frequencies. Only the milk temperature of lame cows deviated from baseline. Thus, acute health disorders (i.e., DA and mastitis) were associated with deviations from those cows' baseline AMS data, whereas more chronic disorders (i.e., SCK and lameness) were associated with significant but subtle longer term changes in milk production and behavior. Because cows with health disorders deviated from a group of healthy cows before they deviated from their own baseline and from the average of all other cows, including a healthy reference group in health alerts could refine the ability of detection models to identify subtle deviations in early lactation.

Key words: robotic milking, behavior, health disorder, detection

\section{INTRODUCTION}

Automated (robotic) milking systems (AMS) collect a vast amount of cow-level data and are often coupled with behavioral monitoring systems (Jacobs and Siegford, 2012). Using these data, many alerts and attention lists are generated to identify cows at risk for developing health problems. Previous research, regardless of milking system, has been focused mostly on detection of mastitis or locomotion problems, with fewer studies looking at metabolic disorders (Rutten et al., 2013). Furthermore, there is little evidence to support which indicators should be used to detect locomotion and metabolic problems (Rutten et al., 2013). Additionally, not all alerts have been validated transparently, nor do they use multiple variables and potentially important covariates (e.g., parity, DIM; King et al., 2017b). For credibility, accuracy, and repeatability, science-based recommendations are needed to generate health attention reports and to select settings for on-farm application, such as the recent development (Kamphuis et al., 2013) and field validation (Kamphuis et al., 2016) of an inline detection system for mastitis and high SCC. Those researchers also consulted industry representa- 
tives for feedback to improve the application of those models (Kamphuis et al., 2016).

Researchers have previously examined associations of changes in rumination, activity, and milk yield data with health disorders in dairy cows, but fewer studies have created and validated prediction models. Daily milk production data followed obvious patterns before and up to $7 \mathrm{~d}$ after clinical ketosis diagnosis (Gröhn et al., 1999) but were less responsive to cases of subclinical ketosis (SCK) and metritis (Gáspárdy et al., 2014). Daily rumination time and BW data changed relative to the day of SCK and metritis diagnoses (Gáspárdy et al., 2014). Rumination time has been shown to decline with the onset of many health disorders, such as mastitis (Fogsgaard et al., 2012; Soriani et al., 2012), inflammatory conditions, metabolic disorders (Soriani et al., 2012), SCK, retained placenta, and metritis (Liboreiro et al., 2015); however, data preceding diagnoses are inherently more useful for earlier diagnoses and intervention if they can predict risk or detect disease more efficiently than the observation of clinical signs. Compared with healthy cows, those diagnosed postpartum with SCK, metritis, or other disorders have been shown to spend less time ruminating before calving (Kaufman et al., 2016; Schirmann et al., 2016). Although there were no differences in prepartum activity between healthy cows and those that later developed SCK, retained placenta, or metritis, the afflicted cows were shown to be less active after calving (Liboreiro et al., 2015). Prior to diagnoses of SCK, displaced abomasum (DA), and digestive disorders, milk yield began to decline approximately 5 to $7 \mathrm{~d}$ before diagnosis and activity started to decline 8 to $9 \mathrm{~d}$ beforehand (Edwards and Tozer, 2004). King et al. (2017b) explored associations of productivity and behavior data before health problems in an AMS herd and found that rumination, activity, and BW data could potentially help to identify DA, pneumonia, SCK, and metritis before changes in milk yield.

Longitudinal milk yield and activity data assessed relative to the day of diagnosis have had great predictive value for detection of lameness when combined with rumination time of parlor-milked cows (Van Hertem et al., 2013) or milk flow rate and AMS teat cup attachment speed (Garcia et al., 2014). Steensels et al. (2016) used a decision tree model to detect ketosis and metritis in AMS-milked cows using milk yield, rumination time, activity, milk slope, and current BW relative to BW at calving to predict the probability of illness. Steensels et al. (2017) also studied health disorders in parlor-milked cows, reporting large differences in rumination time, activity, and milk yield between 5 health status groups (healthy, ketosis, metritis, lameness, and other disorders). Finally, Stangaferro et al. (2016a,b,c) assessed a health index score, comprising rumination and activity data, to detect DA, ketosis, indigestion, mastitis, or metritis. Because the response of individual variables can vary by the type and severity of health disorder (Stangaferro et al., 2016a,b,c), it is possible that predictive models could not only identify cows with potential health problems but perhaps also indicate the type of problem.

Few studies examining behavior and production variables before illness diagnoses have been conducted in AMS (Garcia et al., 2014; Steensels et al., 2016; King et al., 2017b), and those studies consisted of only 1 herd each. Moreover, no large-scale study examined the use of milk yield, rumination, activity, or other electronically collected data to predict a variety of health disorders in AMS herds. Although the overall effects of illness may be similar for AMS and conventionally milked cows, the behavioral freedom associated with free cow traffic and individualized milking could augment the response in AMS because cows are able to extend their milking interval much longer than a conventionally milked cow could.

Therefore, the objective of this study was to examine associations of numerous electronically recorded variables to identify health disorders in early-lactation cows milked by AMS. Rumination, activity, milk yield, and BW data were examined relative to diagnoses of SCK, DA, severe endometritis or purulent vaginal discharge (PVD), lameness, and mastitis with the hypothesis that deviations in those variables would occur before diagnosis. The degree to which each variable deviated was expected to vary by disorder, and we predicted that certain variables would not deviate at all before specific diagnoses. It was further expected that sick cows would deviate from their own healthy baseline at a different time relative to when they deviated from a group of healthy cows but that this could also differ by variable. We also hypothesized that sick cows would deviate from a group of healthy cows before deviating from the average of all other cows.

\section{MATERIALS AND METHODS}

\section{Farms, Animals, and Housing}

This study was approved by the University of Guelph Research Ethics Board (no. 14AP015) and the University of Guelph Animal Care Committee (AUP no. 3140). Farms were selected based on the criteria that they (1) milk Holstein cows exclusively in an AMS (Lely Astronaut A4, Lely Industries N.V., Maassluis, the Netherlands), (2) have done so for a minimum of $6 \mathrm{mo}$, and (3) use the AMS rumination monitoring 
system (Lely Qwes-HR collars, Lely Industries N.V.). These criteria were chosen to minimize variation between farms in terms of milking procedures and data collection. Dairy producers meeting these criteria and located within $<140 \mathrm{~km}$ from the University of Guelph (Guelph, ON, Canada) were contacted and asked to participate in the study. Estimated minimum sample size of the number of cows needed to detect differences in milk yield and rumination time across days among sick cows was determined through power analysis using WinPepi version 11.62 (Abramson, 2011); estimates of standard deviation and differences between days from previous studies were used (Liboreiro et al., 2015; Kaufman et al., 2016; Stangaferro et al., 2016a,b,c). Using documented estimates of SCK (21-44\%; Kaufman et al., 2016; Tatone et al., 2017), DA (5.1\%; LeBlanc et al., 2005), and lameness prevalence (26\%; King et al., 2016), the minimum sample size calculated was 600 cows. To satisfy this requirement, 605 fresh cows from 9 herds were enrolled over a period of 6 mo (June 10, 2016, to December 14, 2016). The entire data collection period lasted 8 mo (May 11, 2016, to January 10, 2017), which extended from $30 \mathrm{~d}$ before calving for the first cows enrolled until the last cows were approximately 30 DIM. The average environmental temperature during the data collection period was $11.5 \pm 9.9^{\circ} \mathrm{C}$, with daily average temperatures ranging from -13.8 to $25.5^{\circ} \mathrm{C}$. Data were retrieved from the Environment Canada weather station in Mount Forest, Ontario, Canada, which was $<70 \mathrm{~km}$ from all farms.

On the first visit to each farm, we surveyed producers on feeding, housing, and health management practices to ensure that we had a thorough understanding of daily routines and herd management to appropriately conduct our data collection. On the day of farm enrollment, producers milked $93 \pm 43$ (mean $\pm \mathrm{SD}$ ) cows with a median of 2 AMS units $(n=4$ farms with 1 unit, $\mathrm{n}=2$ farms with 2 units, $\mathrm{n}=3$ farms with 3 or 4 units). Over the course of the trial, average stocking density at the AMS was $53 \pm 9$ cows per AMS unit. All 9 farms used free cow traffic, and all but 1 housed the main milking herd in freestalls (the other housed cows on a bedded pack). Fresh cows were housed in bedded packs $(\mathrm{n}=1$ farm $)$, freestalls $(\mathrm{n}=4$ farms $)$, or both ( $\mathrm{n}=4$ farms) depending on the farm as well as DIM and health status. Farms were visited once per week, on the same day each week, across the entire study period. In total, 605 cows were enrolled upon freshening (0-7 DIM) and were followed for the first 5 wk of their lactation (496 cows had a full 5-wk period). In total, we monitored 212 primiparous and 393 multiparous cows; the latter were in parity $3.2 \pm 1.4$ (mean $\pm \mathrm{SD}$ ), ranging from second to 11th lactation.

\section{Data Collection}

From 0 to 50 DIM, health disorders were monitored either daily by producers (DA, clinical mastitis) or once per week by researchers (SCK, lameness, and PVD). Producers were given a list of case definitions for illnesses they were responsible for monitoring and recording. A DA was diagnosed by the herd veterinarian when called to the farm by the producer and was defined as a gas-filled abomasum on the left or right side, diagnosed by auscultation of a "ping" sound on percussion. Clinical mastitis was diagnosed by producers when a cow had poor quality or quantity of milk production, as measured by the AMS and abnormal milk or udder upon visual examination, and the cow was treated using an antimicrobial.

We monitored SCK by testing whole-blood BHB concentrations once weekly. Cows were tested for SCK during wk 1 ( $4 \pm 2$ DIM), wk $2(11 \pm 2$ DIM), and wk 3 (18 \pm 2 DIM) postpartum. Blood samples were taken 2 to $4 \mathrm{~h}$ after fresh feed delivery on every farm to collect blood during a window of peak daily BHB (Nikkhah et al., 2008). The concentration of BHB was immediately tested using an electronic hand-held device (Freestyle Neo meter, Abbott Diabetes Care, Mississauga, ON, Canada; validated by Kanz et al., 2015). Cows with $\mathrm{BHB} \geq 1.2 \mathrm{mmol} / \mathrm{L}$ at 1 or more of the 3 postpartum samples were classified as having SCK (McArt et al., 2012). The minimum and maximum BHB concentrations of cows included in this group were 1.2 and 7.2 $\mathrm{mmol} / \mathrm{L}$, respectively.

Purulent vaginal discharge (severe endometritis) was assessed visually by scoring a sample of vaginal discharge during wk 5 of lactation (28-35 DIM) for each cow. The sample was collected using a validated device (Metricheck; Simcro, Hamilton, New Zealand) due to the higher sensitivity of this tool compared with other diagnostic methods (Pleticha et al., 2009). Samples were scored using the scale developed by Sheldon et al. (2006) with stricter classification: cows with a score of 0 to 2 had clear, translucent mucus that contained $\leq 50 \%$ white or off-white material, and cows with a score of 3 were diagnosed with PVD because they had mucus with $>50 \%$ white or off-white material.

Lameness was scored in wk 1, 3, and 5 of lactation by 1 of 2 trained observers by watching cows walk for at least 6 steps on a flat alley surface; observers scored the cows using a 5-point numerical rating system (NRS) at increments of 1.0 (Flower and Weary, 2006). New cases ( $\mathrm{n}=107)$ were defined as cows that previously had NRS $<3$ (in wk 1 or 3 ) but were lame (NRS $\geq 3$ ) when scored 2 wk later (in wk 3 or 5), excluding cows that were lame in wk 1 , sound in wk 3 , and lame again in 
wk 5. Interobserver reliability was assessed before data collection and achieved a weighted kappa value of 0.93 for continuous scores and 1.0 for categorization of lame versus sound.

Milk data were collected automatically by the AMS daily for each cow and retrieved, at each visit, from the AMS computer system. This included visit outcome (refusal, failure, or milking), milk yield, milk temperature, milk conductivity, and amount of concentrate supplement offered. Body weight data were available from 5 of the 9 herds. Daily milk yield was calculated for each cow as the sum of all milk collected per cow per day, whether it was from a successful or a failed milking. Respectively, successful and failed milkings were defined as those at which teat cup attachment was successful or not and whether the amount of milk collected either exceeded or did not meet the system's requirement to qualify as a milking event (i.e., successful attachment and at least $80 \%$ of a cow's expected yield for that milking). From calving up to 50 DIM, milk yield, frequency, temperature, and the frequency of refusals and failures were later converted to 3-d rolling averages to reduce day-to-day variation (due to variable timing of milkings per day), similar to Gomez et al. (2015), in which a 5-d rolling average was used. Maximum daily milk conductivity was determined by taking the highest quarter-level mean milk conductivity value per day.

Rumination time and activity data were collected by electronic rumination detection loggers on the neck collar of each cow in 2-h intervals (Lely Qwes-HR collars, Lely Industries N.V.). The collection of rumination data using these collars has been validated by Schirmann et al. (2009). Cow activity was recorded as a unitless measure of upward, vertical head and neck movements, such as walking and mounting, while excluding downward, vertical and horizontal movements such as feeding (Elischer et al., 2013). The accuracy of these collars' activity data has been validated to an extent in a pasture-based AMS; the collars recorded walking behavior with a moderate degree of accuracy but did not reliably differentiate between standing and lying behavior (Elischer et al., 2013). Only data from complete days ( $24 \mathrm{~h}$ from 0000 to $2359 \mathrm{~h}$ ) were used in analyses. These data were available before calving for 266 of the 605 cows; we collected all days of data available for each cow from up to $30 \mathrm{~d}$ before calving up to 50 DIM and later summarized these values by day for each cow.

\section{Statistical Analyses}

Cows were first grouped into various health status categories. Cows were included in an illness category only if they were affected with only that particular disorder or had that disorder occurring $14 \mathrm{~d}$ or earlier than another disorder. Cows diagnosed with $>1$ illness within $14 \mathrm{~d}$ were excluded from further analyses except for cases of DA, because all 8 cases occurred in conjunction with other disorders (RP, metritis, SCK, lameness). Otherwise, cows would be classified as healthy if they had no detected health problems in the first 5 wk of lactation ( $\mathrm{n}=121$ cows); this group excluded diagnoses of metritis, RP, and milk fever. We also compared cows with each disorder with the average of all cows from all herds, regardless of health status, to serve as a more realistic on-farm comparison. The latter group included all cows other than those with that particular disorder; therefore, this group was made up of a mixture of healthy and sick animals, representative of average herds.

Prior to analyses, all data were screened for normality and outliers using the UNIVARIATE procedure of SAS (version 9.4, SAS Institute Inc., Cary, NC). Outcome variables tested were daily rumination time (min/d), activity (unitless), BW (kg), and 3-d rolling averages for milk yield $(\mathrm{kg} / \mathrm{d})$, frequency of successful milkings (no. of successful milkings/d), frequency of failed milkings (no. of failures/d), frequency of refused milkings (no. of refusals/d), AMS supplement intake $(\mathrm{kg} / \mathrm{d})$, and milk temperature $\left({ }^{\circ} \mathrm{C}\right)$. Failure frequency, refusal frequency, and maximum conductivity data were not always normal and were analyzed using alternative distributions in the GLIMMIX procedure of SAS (version 9.4, SAS Institute Inc.) as described below. Unfortunately, BW data were unavailable for approximately two thirds of cows with health disorders of interest, and thus we could not include BW in our analyses.

Day relative to diagnosis, health status, and their interaction were examined as fixed effects in generalized mixed linear regression models for each disorder separately using the GLIMMIX procedure of SAS (version 9.4, SAS Institute Inc.). Days-to-diagnosis values ranged from $\mathrm{d}-14$ to -1 to include a period during which stable data and deviations in data occurred. We stopped analyses at $d-1$, the nadir in most cases, because recovery began very soon after diagnosis and treatment on d 0 . We examined day-by-day comparisons of affected cows versus healthy cows and of affected cows versus all cows. These 2 reference groups (healthy group and the average group of all cows) were given mock diagnosis dates for comparisons using the mean DIM of diagnosis for each health disorder. Because SCK occurred at 10 DIM, on average, this analysis stopped 8 $\mathrm{d}$ before diagnosis, when the reference groups were at 2 DIM, to avoid highly variable or inconsistent data from 0 and 1 DIM. 
Models included parity (categorized as 1,2 , or $\geq 3$ lactations) and DIM (continuous) as fixed covariates. The random effects in each model were farm, cow within farm, and intercept with subject $=\operatorname{cow}($ farm $)$. Residuals for each model (i.e., for each variable for each health disorder) were examined for normality and homoscedasticity to ensure that the assumptions of linear regression models were met. The normal distribution was most appropriate for the majority of outcome variables. However, failure frequency was always analyzed using the gamma distribution (link $=\log )$ to maximize normality of residuals and achieve the best fit. Refusal frequency was analyzed using the lognormal distribution (link = identity) for all health disorders except DA, for which the gamma distribution was most appropriate. Maximum milk conductivity was analyzed for cows with mastitis, for which the gamma distribution (link $=\log )$ was most appropriate.

A Tukey's test procedure was used to determine day-by-day differences for each outcome variable and to determine the day at which each variable deviated significantly $(P \leq 0.05)$ from the comparison group or its baseline or tended to do so $(P \leq 0.1)$. The baseline of sick animals for each variable was defined as those days between which there were no differences among days $(P>0.1)$ while allowing for a single outlier day. If an outcome variable deviated from the baseline for more than 1 consecutive day $(P \leq 0.1)$, the slope was analyzed between the point at which the variable began to deviate until the nadir at $\mathrm{d}-1$. If no single day of deviation was significant using Tukey's test but the slope between the baseline and a value $2 \mathrm{~d}$ later had $P \leq 0.1$ from baseline, that inflection point was considered the day of deviation. If no deviation occurred, the slope for the entire period preceding diagnosis was quantified. The $P$-values reported for slopes indicate whether they were different from zero.

\section{RESULTS}

This longitudinal, observational study collected rumination, milking behavior, and production data for 605 cows in 9 commercial AMS herds (Table 1). Data included milk yield, milking frequency, failure frequency, refusal frequency, rumination time, AMS supplement intake, BW, milk temperature and conductivity, and cow activity. Those variables were analyzed preceding the diagnosis of numerous fresh cow health disorders (Table 2).

\section{Displaced Abomasum}

Throughout the $14 \mathrm{~d}$ before DA diagnosis, affected cows produced consistently less milk (Figure 1A) in

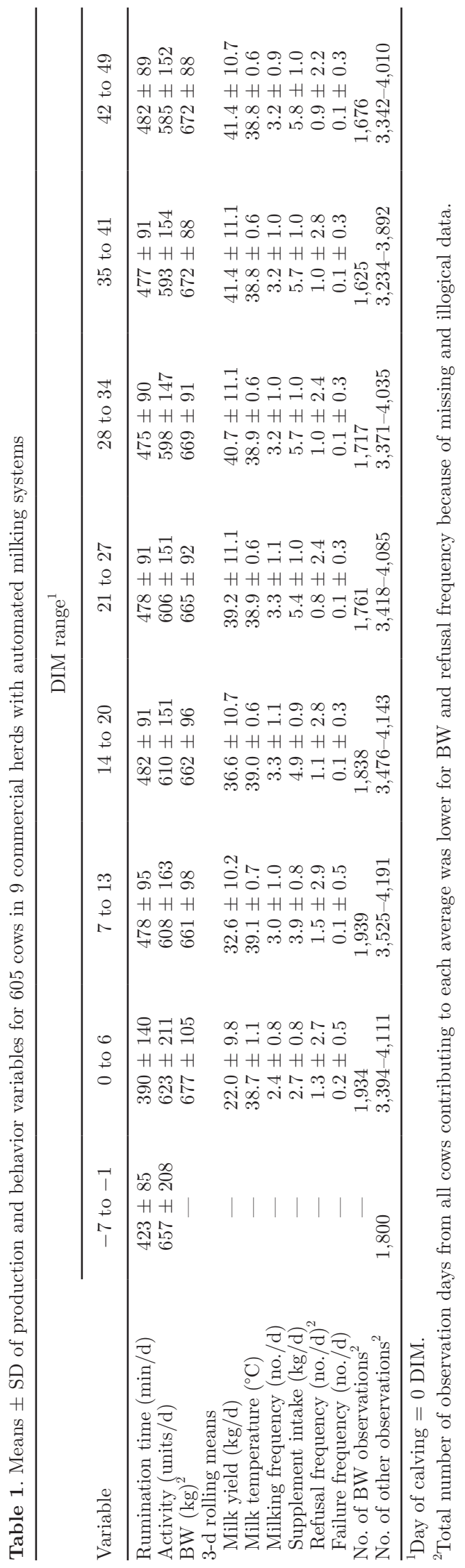

Journal of Dairy Science Vol. 101 No. 5, 2018 
fewer milkings per day (Figure 1E) and spent less time ruminating each day (Figure 1B) than healthy cows. For most of this period, they were also less active compared with healthy animals (Figure 1C). Supplement intake (Figure 1F) and milk temperature (Figure 1D) of cows diagnosed with DA differed from that of healthy cows as of 11 and $3 \mathrm{~d}$ before diagnosis, respectively. There were no differences between healthy and DA cows in mean daily refusal or failure frequency in the $14 \mathrm{~d}$ before diagnosis (data not shown). Among cows diagnosed with DA, milk production deviated from their baseline trajectory at $\mathrm{d}-12$, declining by $1.28 \mathrm{~kg} / \mathrm{d}$ $(P<0.001)$; during that same period, milk yield of healthy cows increased by $0.49 \mathrm{~kg} / \mathrm{d}(P=0.002$; Figure 1A). Rumination time began to decline $12 \mathrm{~d}$ before diagnosis, by $18.9 \mathrm{~min} / \mathrm{d}(P<0.001)$, during which time healthy cows had stable daily rumination time (Figure 1B). Activity deviated from DA cows' baseline trajectory from d -6 onward; cow activity decreased by 20 units/d $(P=0.003)$, whereas healthy cows were stable during this time (Figure 1C). Milk temperature of DA cows deviated from baseline trajectory from d -4 onward by $0.15^{\circ} \mathrm{C}$ each d $(P<0.001$; Figure $1 \mathrm{D})$. Supplement intake and the frequency of milkings, failures, and refusals had no inflection point but steadily declined from $\mathrm{d}-14$ to -1 for DA cows; however, this decline was not significant for refusals (data not shown). Compared with healthy cows, whose supplement intake increased by $75.9 \mathrm{~g} / \mathrm{d}(P<0.001)$ over those $14 \mathrm{~d}$, DA cows consumed $63.6 \mathrm{~g} / \mathrm{d}$ less supplement each day $(P$ $<0.001$; Figure 1F). Frequency of milking and failures for healthy cows was stable over the $14 \mathrm{~d}$, but DA cows were milked 0.062 fewer times/d $(P=0.009$; Figure $1 \mathrm{E})$ and had 0.014 fewer failures/d $(P=0.03$; data not shown) each day from $\mathrm{d}-14$ to -1 relative to diagnosis.

\section{Clinical Mastitis}

For the majority of the period leading up to mastitis diagnoses, affected cows had lower milk production, rumination time, refusal frequency, and milk temperature than healthy cows while having greater maximum milk conductivity values for the entire $14 \mathrm{~d}$ (Figure 2). Starting from $\mathrm{d}-6$ relative to diagnosis, milking frequency (Figure 2E) and supplement intake (data not shown) were lower $(P<0.05$, except $\mathrm{d}-4$ was not significant for supplement intake) compared with healthy cows. Cows were less active for 8 of the $14 \mathrm{~d}$ before mastitis (Figure 2C). There were no differences in frequency of milking failures (data not shown); there was, however, a numerical increase in failure frequency from $d-3$, but this was not statistically significant. Among the cows with mastitis, maximum milk conductivity values began to increase from baseline trajectory from $\mathrm{d}-12$ onward by $1.4 \mathrm{mS} / \mathrm{d}(P<0.001$; Figure $2 \mathrm{~F})$; healthy cows also had increasing conductivity, which was less pronounced $(0.4 \mathrm{mS} / \mathrm{d} ; P=0.01)$. The milking frequency and supplement intake of cows with mastitis declined from baseline trajectory at $\mathrm{d}-8$ and -5 onward, respectively, by 0.1 milkings/d $(P<0.001$; Figure $2 \mathrm{E})$ and $0.04 \mathrm{~kg} / \mathrm{d}(P<0.001$; data not shown $)$ until $\mathrm{d}-1$, whereas healthy cows had stable milking frequency and supplement intake. Rumination time and milk yield of mastitic cows deviated from their baseline trajectory at $\mathrm{d}-8$ and -7 , respectively, decreasing by $10.4 \mathrm{~min} / \mathrm{d}(P$ $<0.001$; Figure 2B) and $1.5 \mathrm{~kg} / \mathrm{d}(P<0.001$; Figure $2 \mathrm{~A}$ ). During the same 8 - and 7 -d periods before mastitis, healthy cows had less severe reductions in rumination time per day $(-8.0 \mathrm{~min} / \mathrm{d} ; P<0.001$; Figure $2 \mathrm{~B})$, and their milk yield declined by $0.6 \mathrm{~kg} / \mathrm{d}(P<0.001$; Figure 3A). Activity, however, declined for healthy cows $(-7.4$ units $/ \mathrm{d} ; P=0.03)$ and those with mastitis $(-7.6$ units/d; $P=0.05$ ); the mastitis group had no obvious inflection point and, thus, activity was examined from $\mathrm{d}-14$ to -1 (Figure $2 \mathrm{C}$ ). There was a visible, but not statistically significant, inflection point at $\mathrm{d}-5$, from which mastitic cows' activity decreased by 21 units/d compared with the 8.3 units/d decrease of healthy cows (Figure 2C). Milk temperature before mastitis diagnosis also had no deviation point, such that both groups of cows had stable milk temperatures during those $14 \mathrm{~d}$ (Figure 2D). Refusal frequency was stable for cows with mastitis but was consistently lower than that of healthy cows from $\mathrm{d}-11$ onward $(P<0.05$; data not shown $)$ and tended to be lower on $\mathrm{d}-13(P=0.10)$.

\section{Development of Lameness}

Compared with healthy cows, those that developed a new case of lameness had lower milk production (Figure 3A) and fewer milkings per day (Figure 3D) throughout the majority of the $14 \mathrm{~d}$ before diagnosis. Cows that became lame generally consumed less supplement than healthy cows from $8 \mathrm{~d}$ before diagnosis onward (Figure $3 \mathrm{E}$ ). Their rumination time was lower than that of healthy cows from d -14 to -12 (Figure 3B). Milk temperature was lower from $\mathrm{d}-14$ to -8 and from $\mathrm{d}-5$ to -1 (Figure $3 \mathrm{C}$ ) for cows that became lame. Only on $\mathrm{d}-12$ did cows that became lame have fewer refusals (Figure 3F). Those cows also tended to have more milking failures on $\mathrm{d}-9$ and $-8(P<0.1$; data not shown). Activity levels never differed between these groups (data not shown). Among cows that developed a new case of lameness, milk temperature increased by $0.027^{\circ} \mathrm{C} / \mathrm{d}$ until an inflection point at $\mathrm{d}-6$, when it began to decline by $0.032^{\circ} \mathrm{C} / \mathrm{d}$ (Figure 3C). However, no deviations in milk yield (Figure 3A), rumination time (Figure 3B), milking frequency (Figure 3D), supple- 
Table 2. Summary of health disorders diagnosed and the DIM of diagnoses in 9 commercial herds with automated milking systems ${ }^{1}$

\begin{tabular}{|c|c|c|c|c|c|c|}
\hline \multirow[b]{2}{*}{ Health disorder } & \multirow[b]{2}{*}{$\mathrm{n}$} & \multicolumn{5}{|c|}{ DIM at diagnosis } \\
\hline & & Mean & Median & $\mathrm{SD}$ & Minimum & Maximum \\
\hline \multicolumn{7}{|l|}{ All cases observed } \\
\hline Displaced abomasum (DA) & 8 & 22 & 18 & 15 & 8 & 49 \\
\hline Mastitis & 38 & 16 & 14 & 13 & 0 & 46 \\
\hline New case of lameness & 107 & 24 & 21 & 7 & 14 & 35 \\
\hline Subclinical ketosis & 198 & 10 & 8 & 6 & 1 & 21 \\
\hline Purulent vaginal discharge (PVD) & 114 & 32 & 32 & 2 & 28 & 36 \\
\hline \multicolumn{7}{|l|}{ Cases analyzed ${ }^{2}$} \\
\hline $\mathrm{DA}^{2}$ & 8 & 22 & 18 & 15 & 8 & 49 \\
\hline Mastitis & 13 & 16 & 13.5 & 13 & 3 & 38 \\
\hline New case of lameness & 45 & 23 & 20 & 7 & 15 & 35 \\
\hline Subclinical ketosis & 113 & 10 & 8 & 6 & 1 & 21 \\
\hline PVD & 49 & 32 & 32 & 2 & 28 & 35 \\
\hline
\end{tabular}

${ }^{1}$ Data were collected on 605 cows.

${ }^{2}$ Analyses were limited to include cows that were sick with only that particular disorder, or that disorder occurring $14 \mathrm{~d}$ or earlier than another disorder. However, for DA, all 8 cases occurred in conjunction with other disorders.
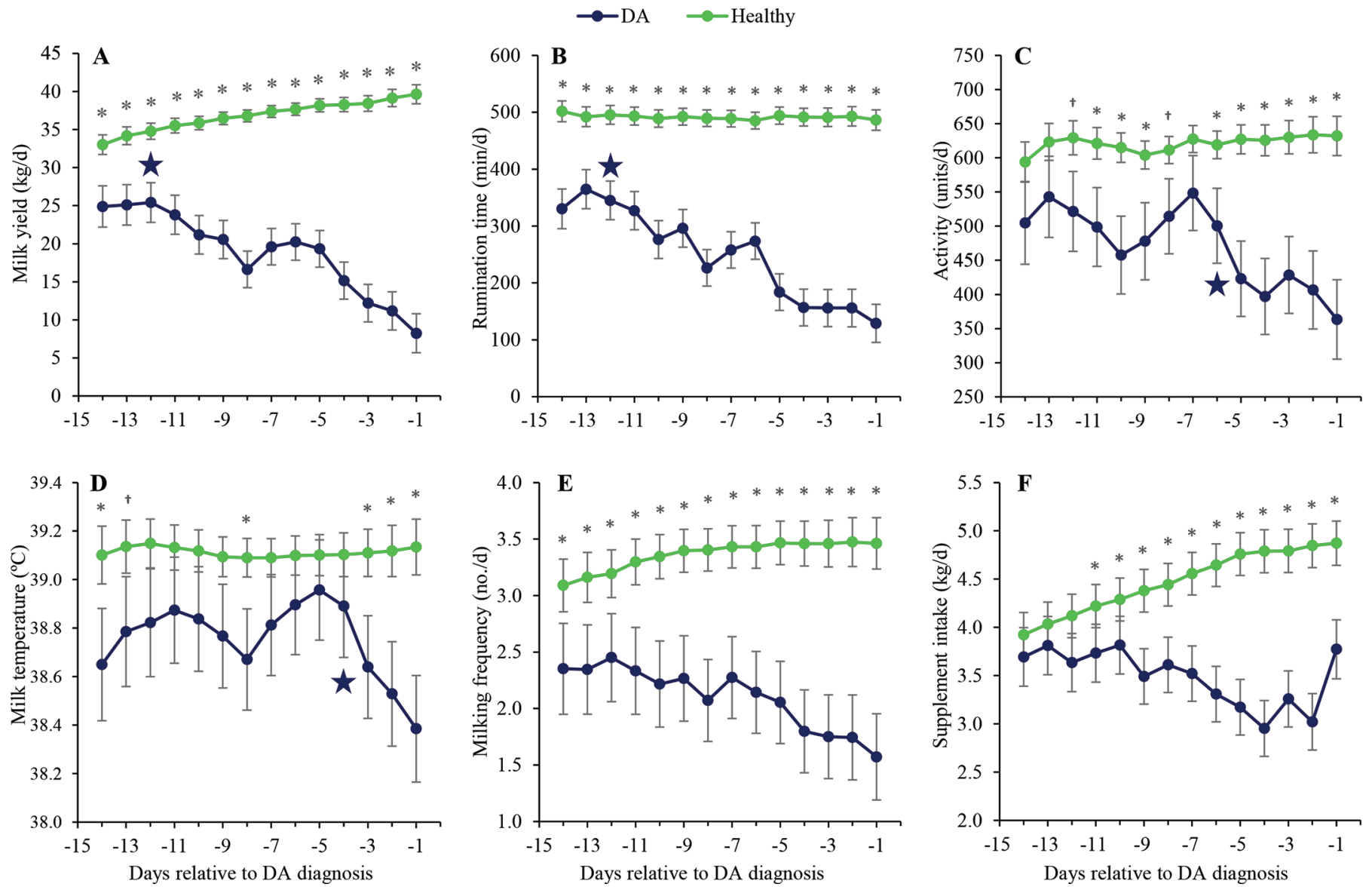

Figure 1. Data from d -14 to -1 relative to diagnosis for cows with displaced abomasum (DA; $n=7-8)$ compared with healthy cows $(\mathrm{n}$ $=121$ ) given a mock diagnosis date using the mean DIM at diagnosis for DA cows (22 DIM). Graphs show LSM \pm SE accounting for DIM and parity for the following variables: (A) milk yield, (B) rumination time, (C) activity, (D) milk temperature, (E) milking frequency, and (F) supplement intake. *Significant $(P \leq 0.05)$ differences; †tendency $(P \leq 0.1)$ between healthy and DA cows' LSM in daily pair-wise comparisons. Star symbol indicates deviation of $\overline{\mathrm{D}} \mathrm{A}$ cows from their own baseline. Color version available online. 
ment intake (Figure 3E), failure frequency (data not shown), or refusal frequency (Figure 3F) occurred from baseline trajectory for cows that developed lameness. Examination of slopes over the 14-d period revealed no significant change in milk yield, rumination time, milking frequency, or refusal frequency for lame cows. Healthy cows had a stable frequency of failed milkings, but lame cows tended to have 0.007 more failures/d each day from $\mathrm{d}-14$ to -1 ( $P=0.08$; data not shown). Lame cows had no change in their supplement intake over the $14 \mathrm{~d}$, whereas healthy cows consumed 28.8 $\mathrm{g} / \mathrm{d}$ more supplement each day $(P=0.005$; Figure $3 \mathrm{E})$. Both lame and healthy groups had declining activity over the $14 \mathrm{~d}$, but healthy cows had a steeper reduction $(P=0.05 ;$ data not shown $)$.

\section{Subclinical Ketosis}

During much of the $8 \mathrm{~d}$ before SCK detection, cows consumed less supplement and had fewer milkings per day and refusals per day compared with healthy cows (Figure 4). Only from d -5 to -3 did SCK cows produce less milk, and on $\mathrm{d}-8$ they produced more milk than healthy cows (Figure 4A). Cows with SCK also spent less time ruminating (Figure 4B), tended to be less active $(P<0.05$ on $\mathrm{d}-8,-7$, and -1 , and $P=0.10$ on $\mathrm{d}-3$; data not shown), and had lower milk temperatures (Figure $4 \mathrm{C}$ ). No differences were seen between groups in terms of the frequency of failed milkings. Among cows with SCK, there were no inflection points for any variable. Therefore, from $\mathrm{d}-8$ to -1 , cows with SCK had stable milk yield (Figure 4A), milk temperature (Figure 4C), supplement intake (Figure $4 \mathrm{E}$ ), refusal frequency (Figure $4 \mathrm{~F}$ ), and failure frequency (data not shown). Rumination time of SCK cows gradually declined by $4.1 \mathrm{~min} / \mathrm{d}$ over the $8 \mathrm{~d}(P$ $=0.01 ;$ Figure $4 \mathrm{~B})$. In comparison, healthy cows had stable rumination time in addition to stable supplement intake (Figure 4E) and failures per day (data not shown). The refusal frequency of healthy cows increased
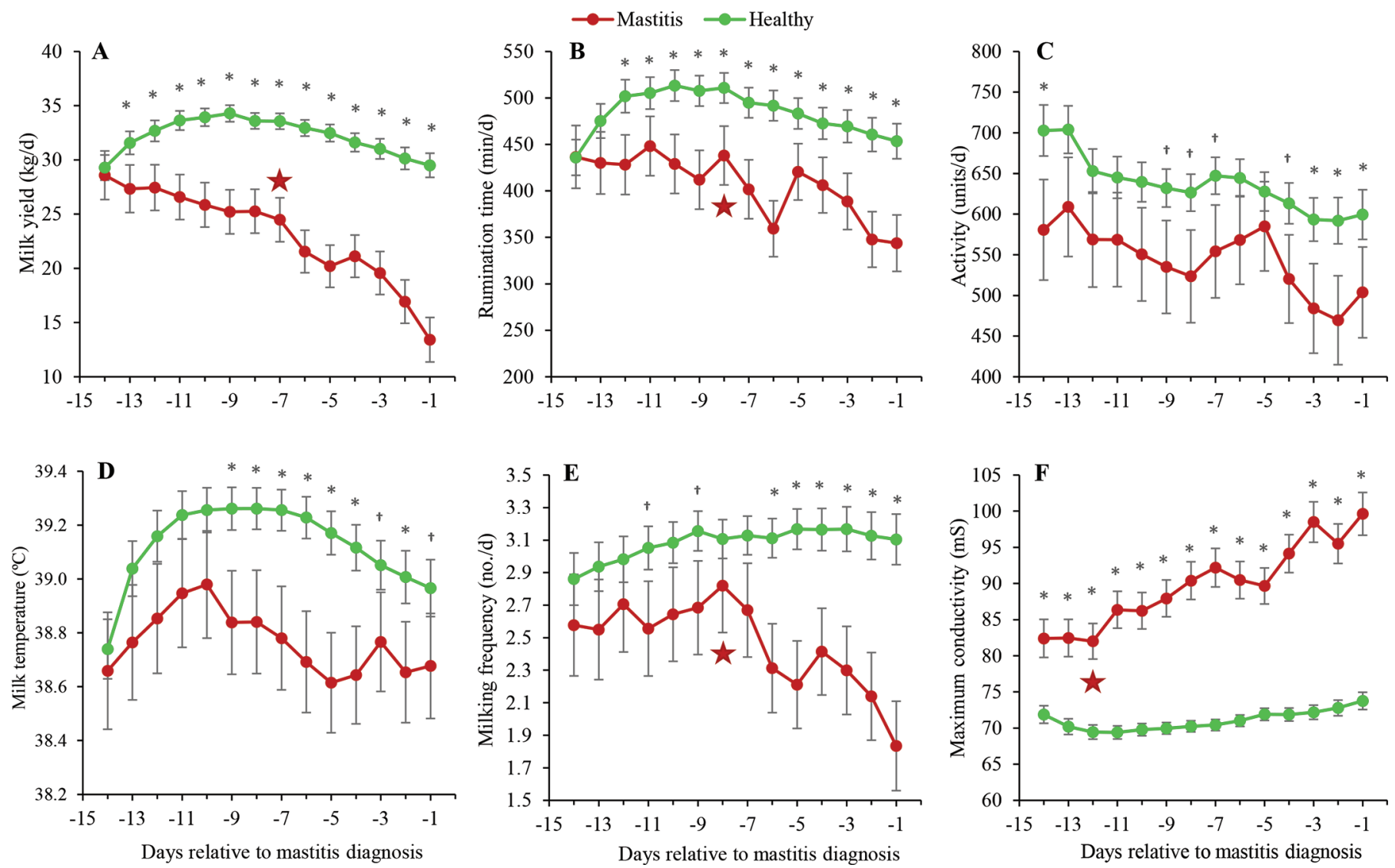

Figure 2. Data from d -14 to -1 relative to diagnosis of treated clinical mastitis $(\mathrm{n}=7-13)$ compared with healthy cows $(\mathrm{n}=121)$ given a mock diagnosis date using the mean DIM at diagnosis of mastitis (16 DIM). Graphs show LSM \pm SE accounting for DIM and parity for the following variables: (A) milk yield, (B) rumination time, (C) activity, (D) milk temperature, (E) milking frequency, and (F) maximum milk conductivity. *Significant $(P \leq 0.05)$ differences; †tendency $(P \leq 0.1)$ between healthy and mastitic cows' LSM in daily pair-wise comparisons. Star symbol indicates deviation of cows with mastitis from their own baseline. Color version available online. 

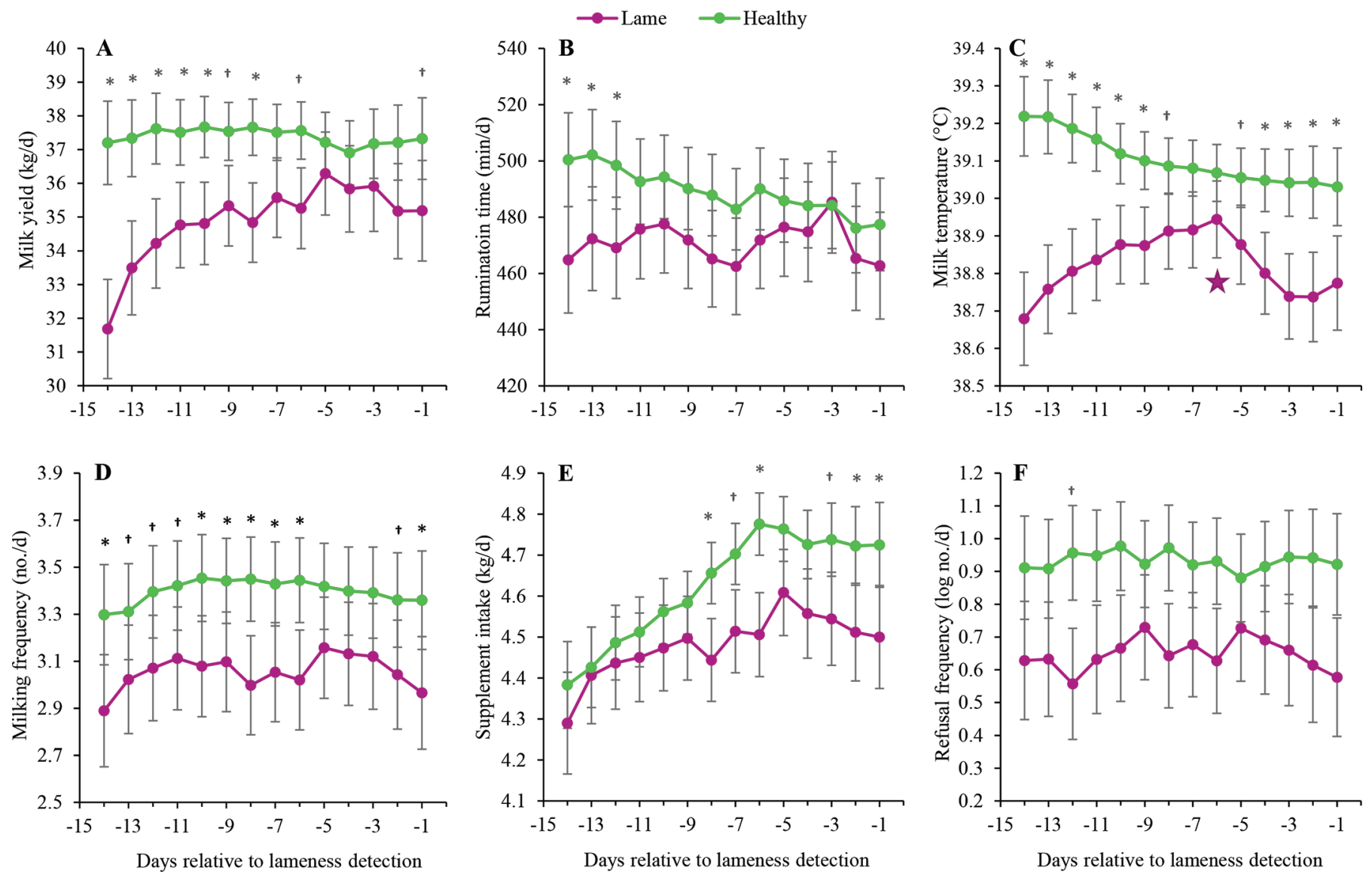

Figure 3. Data from $\mathrm{d}-14$ to -1 relative to detection of new cases of lameness $(\mathrm{n}=45)$ compared with healthy cows $(\mathrm{n}=121)$ given a mock diagnosis date using the mean DIM at diagnosis for lameness (23 DIM). Graphs show LSM \pm SE accounting for DIM and parity for the following variables: (A) milk yield, (B) rumination time, (C) milk temperature, (D) milking frequency, (E) supplement intake, and (F) refusal frequency. *Significant $(P \leq 0.05)$ differences; †tendency $(P \leq 0.1)$ between healthy and lame cows' LSM in daily pair-wise comparisons. Star symbol indicates deviation of lame cows from their own baseline. Color version available online.

during this period $(P<0.001)$, as did their milk yield $(P<0.001)$ and milk temperature $(P=0.002)$. Both groups had increasing milk frequency and decreasing activity, but the rate of change in milk frequency $(P$ $=0.02$; Figure 1D) and activity $(P=0.01$; data not shown) was greater for SCK cows.

\section{PVD (Severe Endometritis)}

The only differences observed between healthy cows and those with PVD (data not shown) were in milk yield on $\mathrm{d}-11$ and -10 , rumination time on $\mathrm{d}-12$, -11 , and -4 , and milk temperature on $\mathrm{d}-14$, when cows that later developed PVD had lower milk yield, greater rumination time, and higher milk temperature. No differences were seen between groups in terms of activity, milk frequency, frequency of failures, or refusals. No deviations from baseline trajectory occurred among cows with PVD. Therefore, data were analyzed from d
-14 to -1 , during which time both groups had slopes that were not different from 0 , but slopes of those groups differed from each other. Milk yield declined more rapidly for healthy cows $(P=0.03)$, whereas milk temperature $(P=0.01)$ and activity $(P=0.03)$ declined faster for cows with PVD.

\section{Comparing to a Reference Population of All Cows}

Comparisons of each health disorder against the average of all cows (instead of the healthy reference group) revealed results similar to those described above. However, there were fewer differences between groups in daily pairwise comparisons, and sick cows generally differed from this average group later than they differed from the healthy group. For example, cows with mastitis still had lower rumination time and milk yield than the average group (data not shown), but daily comparisons between the mastitis and average 
groups differed $2 \mathrm{~d}$ later for rumination $(\mathrm{d}-10$ instead of $\mathrm{d}-12)$ and milk yield ( $\mathrm{d}-11$ instead of $\mathrm{d}-13$ ) compared with the earlier analysis against the healthy group. This was commonly the case for comparisons of mastitis, SCK, and DA relative to the average of all cows, which had fewer days that were significantly different between groups. New cases of lameness, however, had even fewer significant differences in these comparisons. Milk yield and milking frequency of lame cows were lower than the average group for only $1 \mathrm{~d}$ instead of several, and rumination time did not differ between groups on any day, whereas before there were $3 \mathrm{~d}$ that differed. When comparing the group of cows that became lame with the average of all other cows (instead of with the healthy group), differences in milk temperature and supplement intake were very similar, although some significant differences became tendencies, and the 1 difference in refusal frequency on $\mathrm{d}-12$ was no longer significant.

\section{DISCUSSION}

Relative to their baseline trajectory, cows diagnosed with acute health disorders (DA and mastitis) exhibited significant deviations in productivity and behavior before diagnosis. Milk yield and rumination time declined sharply for affected animals before both disorders; cows with DA also had deviations in activity and milk temperature, whereas cows with mastitis had deviations in milking frequency and supplement intake. Fogsgaard et al. (2012) previously reported similar changes in behavior occurring with the onset of induced mastitis in terms of feeding time, rumination time, self-grooming, and time spent in a posture with the head against the udder. Naturally occurring mastitis has previously been associated with reduced activity from $5 \mathrm{~d}$ before diagnosis compared with healthy cows, and cows with mastitis had declining rumination and activity from 2 $\mathrm{d}$ before diagnosis (Stangaferro et al., 2016b). Those
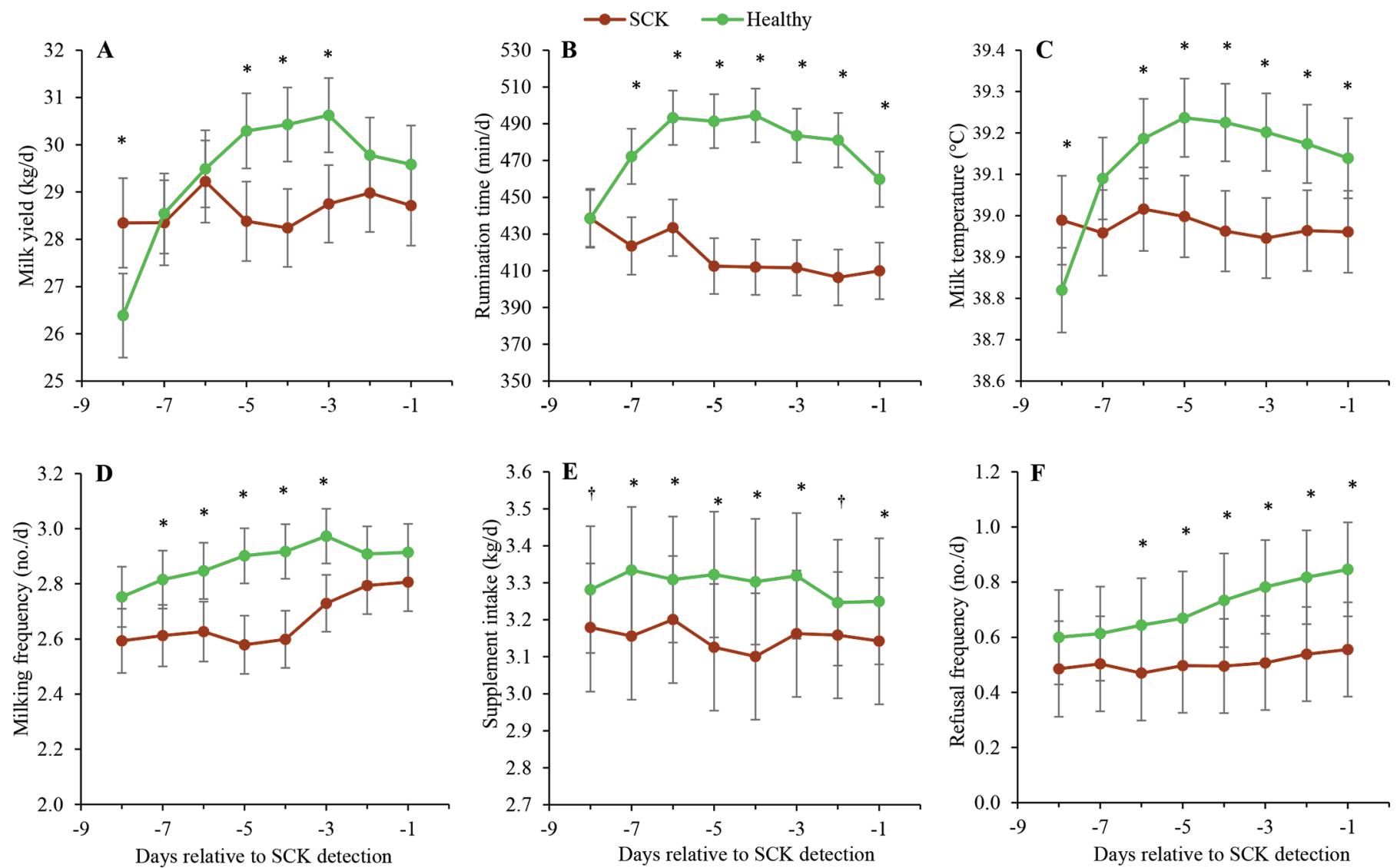

Figure 4. Data from d -8 to -1 relative to diagnosis of subclinical ketosis (SCK; blood BHB $>1.2 \mathrm{mmol} / \mathrm{L}$ at least once during the first 3 wk of lactation; $\mathrm{n}=88-113)$ compared with healthy cows ( $\mathrm{n}=121)$ given a mock diagnosis date using the mean DIM at diagnosis (10 DIM). Graphs show LSM \pm SE accounting for DIM and parity for the following variables: (A) milk yield, (B) rumination time, (C) milk temperature, (D) milking frequency, $(\mathrm{E})$ supplement intake, and $(\mathrm{F})$ refusal frequency. ${ }^{*}$ Significant $(P \leq 0.05)$ differences; $†$ tendency $(P \leq 0.1)$ between healthy and SCK cows' LSM in daily pair-wise comparisons. Color version available online. 
researchers did not observe the difference in rumination time between groups as seen in the present study, nor did they report the early response of rumination data $7 \mathrm{~d}$ before mastitis diagnoses. Stangaferro et al. (2016a) did, however, find associations similar to the current study with regard to rumination and activity before DA: cows with DA had lower rumination time and activity compared with healthy animals $5 \mathrm{~d}$ before diagnosis of DA, and these variables declined leading up to diagnosis. Edwards and Tozer (2004) also noted declining activity (from $\mathrm{d}-9$ ) and milk yield (from $\mathrm{d}$ -7 ) before DA diagnosis; those changes occurred $3 \mathrm{~d}$ before and $4 \mathrm{~d}$ after, respectively, deviations found in the current study.

In contrast, the more chronic health disorders did not exhibit those sharp deviations in the current study; behavior and production had a more gradual response to SCK and lameness. In fact, most variables before SCK were stable, and those that changed did so gradually. Cows that developed a new case of lameness had one inflection point in milk temperature $6 \mathrm{~d}$ before diagnosis; otherwise, lame cows had stable milk yield, supplement intake, rumination time, milking frequency, and refusal frequency over the $14 \mathrm{~d}$ before diagnosis. Milk yield and rumination time were generally lower for lame and SCK cows, but there was no difference in activity compared with healthy animals. Alternatively, Van Hertem et al. (2013) reported gradual changes in milk yield and activity data before lameness; visually, however, 2 reductions in nighttime rumination activity occurred from $\mathrm{d}-7$ to -6 and from $\mathrm{d}-1$ to 0 relative to diagnosis of lameness. Stangaferro et al. (2016a) saw similar gradual reductions in rumination time and activity before SCK diagnosis, and Steensels et al. (2017) observed lower activity and rumination time in ketotic and lame cows compared with healthy cows. In the current study, any differences between healthy animals and those that had a state-like disorder mostly resulted in gradual deviations between groups, already present 7 to $14 \mathrm{~d}$ before diagnosis, or because either group was stable while the other slowly deviated. As such, because of the subtle changes over time, these disorders may be more difficult to detect using automated health monitoring systems.

Rumination data exhibited earlier deviations from baseline trajectory than milk yield data. Prior to mastitis diagnoses, rumination time deviated from baseline $1 \mathrm{~d}$ before the response in milk yield, on average. The response of rumination at least $1 \mathrm{~d}$ before milk data was previously reported by King et al. (2017b) before diagnosis of SCK, pneumonia, and DA in a research herd with AMS. Health alerts should, thus, flag cows with declining rumination behavior before their declining milk yield. In the current study, milking frequency also declined earlier than milk yield. However, the magnitude of these changes, although statistically significant, may be so subtle in practical settings that any observed change in milking frequency may not be useful for daily health monitoring.

Comparing sick cows with a group of healthy cows allowed us to detect certain differences much earlier than when just looking for deviations from the baseline trajectory of those sick cows. This finding may not necessarily translate to better illness detection on farm, but a healthy comparison group could be a very useful refinement to existing algorithms and should be pursued in future research. Comparison with a healthy group should complement the current monitoring of cows relative to their own baseline trajectory. In addition to the healthy group, we compared cows with health disorders with all cows from participating study herds. This comparison was designed to mimic the reference group that would typically be used on farm. As expected, these comparisons demonstrated similar findings as earlier described but had delayed or fewer significant differences between the sick and comparison group. This suggests that the use of a reference group of cows that are healthy, with similar DIM, could enable earlier and more meaningful comparisons for on farm health monitoring. This would require AMS software to combine treatment and health information with historical lactation data to create trajectories of previously healthy fresh cows to use as a target when monitoring current fresh cows. Although this approach would create reports with herd-specific lactation trajectories based on feed, climate, and so on, this comparison could also be confounded with time and changes in management. Future research is therefore needed to test this approach and to establish the necessary interval for resetting such reports (e.g., with every feed change).

Certain metrics showed variable responses by disorder. For example, activity levels associated with most disorders either were lower overall or declined before diagnosis (similar to cows with ketosis, DA, and mastitis; Stangaferro et al., 2016a,b) except for new cases of lameness, where activity of both healthy and lame cows declined at similar rates. King et al. (2017a,b) also found no associations of activity with lameness, which is in contrast with a previous study that used the same activity monitors and found decreasing daytime activity before lameness diagnosis (Van Hertem et al., 2013). It is important to note that the neck collar activity monitors used in the current study have not been openly validated for illness detection and were only moderately reliable for walking behavior in a previous study with a pasture-based AMS (Elischer et al., 2013). Although these monitors have been validated for estrus detection and are more efficient and accurate 
than visual monitoring for that purpose (Michaelis et al., 2014), they have lower efficacy for detecting estrus of cows with BCS $<2$ and above-average milk yield (>54 L/d; Holman et al., 2011). Despite the reduced mobility of lame cows, the neck collar activity monitors did not have reduced heat detection accuracy for cows with NRS $\geq 2$ out of 5 (Holman et al., 2011). We speculate that there may be no difference with new cases of lameness because of great variability in activity between and within cows. Also, lame cows in this study and in King et al. (2017a) were mostly NRS $=3$; very few cows had NRS $>3$, and most sound cows had NRS $=2$. It is possible that a 1-unit increase in locomotion score is not enough to cause differences in activity using this specific monitoring device; thus, more research is required to assess whether data collected by this or other activity monitors can be used to detect lameness.

Other metrics, such as milk temperature, deviated from those cows' baseline trajectory only before DA and lameness. Milk temperature began to decline $4 \mathrm{~d}$ before diagnosis of DA at a similar rate reported by King et al. (2017b), which may be reflective of the reduction in rumination time seen in both studies before DA. Simmons et al. (1965) and Bitman et al. (1984) observed elevated body temperatures associated with eating, likely representative of the heat increment of feeding. Because milk and body temperatures are highly correlated (Schutz and Bewley, 2009), it can be hypothesized that reduced feed intake and rumination time would be associated with lower body and milk temperatures. In a study by Wenz et al. (2011), cows with metabolic or digestive disorders tended to have higher temperatures than healthy cows during 5 of the first 10 DIM and a noticeable decrease in temperature around 6 to 7 DIM, but this was not examined statistically. Prior to lameness, we would have expected milk temperature to increase as it did in the study by King et al. (2017b). Instead, milk temperature increased until $\mathrm{d}-6$ and then began to decline. A recognized limitation of this study is that we diagnosed lameness only once every $2 \mathrm{wk}$, SCK once per week, and PVD once total. As a result, the day we diagnosed these disorders was not necessarily the same day that cows developed a certain condition. We could therefore speculate that changes in milk temperature before lameness detection reflect increasing body temperature with lameness development because certain causes of lameness can increase body temperature (Adams et al., 2013). Then, milk temperature may begin to decline as cows eat and ruminate less (Simmons et al., 1965; Bitman et al., 1984). Milk temperature before SCK and mastitis diagnoses was stable but also lower than that of healthy cows, who had increasing milk temperature from 2 to 5 DIM. This "healthy" trend for increasing milk temperature is comparable with rectal temperatures reported for cows between 1 and 3 to 4 DIM (Burfeind et al., 2014); however, those authors reported increased body temperature with SCK in primiparous cows and with abnormal vaginal discharge in primiparous and multiparous cows. Similar to those results, Adams et al. (2013) observed increasing reticular temperature with mastitis and pneumonia but not with lameness or metritis, and Wenz et al. (2011) reported associations of increasing body temperature with infectious health events (mastitis, metritis, or pneumonia). The current study found no increase in temperature with mastitis, and King et al. (2017b) found no association before pneumonia. Thus, more research is required to understand the potential use of milk temperature monitoring in AMS to detect health disorders.

Finally, milking frequency and supplement intake deviated from the baseline trajectory only of cows with mastitis and did not do so for any other health disorder. We hypothesized that even mild cases of mastitis would reduce milking frequency due to discomfort or pain associated with milking. Stepping behavior during milking in AMS has been positively associated with SCC, suggesting that cows were more unsettled (Gygax et al., 2008) and cows with induced mastitis exhibited behavioral responses indicative of pain and discomfort (Fogsgaard et al., 2012). With cows being less willing to visit the AMS to milk, their milking frequency would decline, and because supplement allowance is sometimes based on production (and indirectly on milking frequency), reduced supplement intake was expected as well. What we did not observe was an increase in milking failures before mastitis, which was expected based on field observations of AMS having difficulty successfully milking cows with mastitis, due to either attachment issues or numerous kick-offs by cows that are likely uncomfortable or in pain. In our preliminary analyses of all cases of mastitis, regardless of other health conditions $(\mathrm{n}=38)$, we did see an increasing number of failed milking before the day of clinical mastitis diagnosis, but this was not significant in the reported analyses of independently occurring cases of mastitis $(\mathrm{n}=13)$.

Like King et al. (2017b), we controlled for DIM and parity in our analyses. These 2 covariates are crucial to account for cow-level differences in early lactation, when fresh cows should have increasing milk yield and rumination time each day and activity is expected to slowly decline (Liboreiro et al., 2015). Changes in milk and rumination are expected to be more pronounced for older cows, who generally produce more, ruminate more, and are less active than younger cows (King et al., 2017a). Most of the current health alert systems do not take parity and DIM into account and thus use the same threshold for early- and late-lactation cows 
regardless of parity. If these algorithms considered parity and stage of lactation, they would be more sensitive to subtle changes in metrics of sick fresh cows (true positives) while not flagging late-lactation cows with similar deviations who are, in fact, healthy (false positives). It is also important to emphasize that data presented here are least squares means from models that controlled for DIM and parity; the figures do not include cow-specific trajectories, which will differ by individual. It is also possible that the day an illness was diagnosed was delayed from the true onset of a disease, particularly for disorders monitored by researchers. The variation between cases and between farms could have been 1 to $6 \mathrm{~d}$; however, for very severe illness diagnosed by producers and occasionally by veterinarians, it is likely that the delay would not be more than $1 \mathrm{~d}$. Future research is required to identify the sensitivity and specificity of using various thresholds of deviation values or slopes to accurately identify health disorders in fresh cows in AMS herds.

\section{CONCLUSIONS}

In summary, acute health disorders, such as DA and mastitis, were associated with noticeable deviations from those cows' baseline trajectory AMS data occurring 4 to $12 \mathrm{~d}$ before diagnosis. More chronic disorders, such as SCK and lameness, were associated with significant but subtle longer term changes in productivity and behavior. Cows with health disorders generally deviated from a group of healthy cows before they deviated from their own baseline and before deviating from the average of all other cows. Therefore, in addition to examining cows relative to their own baseline trajectory and accounting for DIM and parity, including a healthy reference group could improve the sensitivity of alerts that may be used to identify more subtle deviations in these metrics during early lactation.

\section{ACKNOWLEDGMENTS}

We are especially grateful to the participating producers who allowed us access to their animals and AMS data. Robyn Walsh (Grand River Robotics, Fergus, ON, Canada) kindly helped us recruit farms and provided technical support throughout the project. Thank you to those who helped collect data, including Emily Kaufman, Felipe Pádua, Isabela Salmazo, Kaitlin Sparkman, Michelle Thompson, and Sarah McPherson, all from the University of Guelph (Guelph, ON, Canada). This project was financially supported by a contribution from the Dairy Research Cluster II Initiative, funded by the Dairy Farmers of Canada (Ottawa, ON, Canada), Agriculture and Agri-Food Canada (Ottawa,
ON, Canada), the Canadian Dairy Network (Guelph, ON, Canada), and the Canadian Dairy Commission (Ottawa, ON, Canada), as well as in part by funding from the Canada First Research Excellence Fund (Ottawa, ON, Canada).

\section{REFERENCES}

Abramson, J. H. 2011. WINPEPI updated: Computer programs for epidemiologists, and their teaching potential. Epidemiol. Perspect. Innov. 8:1. https://doi.org/10.1186/1742-5573-8-1.

Adams, A. E., F. J. Olea-Popelka, and I. N. Roman-Muniz. 2013. Using temperature-sensing reticular boluses to aid in the detection of production diseases in dairy cows. J. Dairy Sci. 96:1549-1555. https://doi.org/10.3168/jds.2012-5822.

Bitman, J., A. Lefcourt, D. L. Wood, and B. Stroud. 1984. Circadian and ultradian temperature rhythms of lactating dairy cows. J. Dairy Sci. 67:1014-1023. https://doi.org/10.3168/jds.S0022 -0302(84)81400-9.

Burfeind, O., V. S. Suthar, R. Voigtsberger, S. Bonk, and W. Heuwieser. 2014. Body temperature in early postpartum dairy cows. Theriogenology 82:121-131. https://doi.org/10.1016/j.theriogenology 2014.03.006.

Edwards, J. L., and P. R. Tozer. 2004. Using activity and milk yield as predictors of fresh cow disorders. J. Dairy Sci. 87:524-531. https:// doi.org/10.3168/jds.S0022-0302(04)73192-6.

Elischer, M. F., M. E. Arceo, E. L. Karcher, and J. M. Siegford. 2013. Validating the accuracy of activity and rumination monitor data from dairy cows housed in a pasture-based automatic milking system. J. Dairy Sci. 96:6412-6422. https://doi.org/10.3168/jds.2013 -6790 .

Flower, F. C., and D. M. Weary. 2006. Effect of hoof pathologies on subjective assessments of dairy cow gait. J. Dairy Sci. 89:139-146. https://doi.org/10.3168/jds.S0022-0302(06)72077-X.

Fogsgaard, K. K., C. M. Røntved, P. Sørensen, and M. S. Herskin. 2012. Sickness behavior in dairy cows during Escherichia coli mastitis. J. Dairy Sci. 95:630-638. https://doi.org/10.3168/jds.2011 -4350 .

Garcia, E., I. Klaas, J. M. Amigo, R. Bro, and C. Enevoldsen. 2014. Lameness detection challenges in automated milking systems addressed with partial least squares discriminant analysis. J. Dairy Sci. 97:7476-7486. https://doi.org/10.3168/jds.2014-7982.

Gáspárdy, A., G. Efrat, A. C. Bajcsy, and S. G. Fekete. 2014. Electronic monitoring of rumination activity as an indicator of health status and production traits in high-yielding dairy cows. Acta Vet. Hung. 62:452-462. https://doi.org/10.1556/AVet.2014.026.

Gomez, A., N. B. Cook, M. T. Socha, and D. Döpfer. 2015. Firstlactation performance in cows affected by digital dermatitis during the rearing period. J. Dairy Sci. 98:4487-4498. https://doi.org/10 $.3168 /$ jds.2014-9041.

Gröhn, Y. T., J. J. McDermott, Y. H. Schukken, J. A. Hertl, and S. W. Eicker. 1999. Analysis of correlated continuous repeated observations: Modelling the effect of ketosis on milk yield in dairy cows. Prev. Vet. Med. 39:137-153. https://doi.org/10.1016/S0167 $-5877(98) 00145-7$.

Gygax, L., I. Neuffer, C. Kaufmann, R. Hauser, and B. Wechsler. 2008. Restlessness behaviour, heart rate and heart-rate variability of dairy cows milked in two types of automatic milking systems and auto-tandem milking parlours. Appl. Anim. Behav. Sci. 109:167-179. https://doi.org/10.1016/j.applanim.2007.03.010.

Holman, A., J. Thompson, J. E. Routly, J. Cameron, D. N. Jones, D. Grove-White, R. F. Smith, and H. Dobson. 2011. Comparison of oestrus detection methods in dairy cattle. Vet. Rec. 169:47. https://doi.org/10.1136/vr.d2344.

Jacobs, J. A., and J. M. Siegford. 2012. Invited review: The impact of automatic milking systems on dairy cow management, behavior, health, and welfare. J. Dairy Sci. 95:2227-2247. https://doi.org/ $10.3168 /$ jds.2011-4943. 
Kamphuis, C., B. Dela Rue, G. Mein, and J. Jago. 2013. Development of protocols to evaluate in-line mastitis detection systems. J. Dairy Sci. 96:4047-4058. https://doi.org/10.3168/jds.2012-6190.

Kamphuis, C., B. T. Dela Rue, and C. R. Eastwood. 2016. Field validation of protocols developed to evaluate in-line mastitis detection systems. J. Dairy Sci. 99:1619-1631. https://doi.org/10.3168/jds .2015-10253.

Kanz, P., M. Drillich, D. Klein-Jöbstl, B. Mair, S. Borchardt, L. Meyer, I. Schwendenwein, and M. Iwersen. 2015. Suitability of capillary blood obtained by a minimally invasive lancet technique to detect subclinical ketosis in dairy cows by using 3 different electronic handheld devices. J. Dairy Sci. 98:6108-6118. https://doi .org/10.3168/jds.2014-8957.

Kaufman, E. I., S. J. LeBlanc, B. W. McBride, T. F. Duffield, and T. J. DeVries. 2016. Association of rumination time with subclinical ketosis in transition dairy cows. J. Dairy Sci. 99:5604-5618. https://doi.org/10.3168/jds.2015-10509.

King, M. T. M., K. M. Dancy, S. J. LeBlanc, E. A. Pajor, and T. J. DeVries. 2017b. Deviations in behavior and productivity data before diagnosis of health disorders in cows milked with an automated system. J. Dairy Sci. 100:8358-8371. https://doi.org/10 $.3168 /$ jds.2017-12723.

King, M. T. M., S. J. LeBlanc, E. A. Pajor, and T. J. Devries. 2017a Cow-level associations of lameness, behavior, and milk yield of cows milked in automated systems. J. Dairy Sci. 100:4818-4828. https://doi.org/10.3168/jds.2016-12281.

King, M. T. M., E. A. Pajor, S. L. LeBlanc, and T. J. DeVries. 2016 Associations of herd-level housing, management, and lameness prevalence with productivity and cow behavior in herds with automated milking systems. J. Dairy Sci. 99:9069-9079. https://doi .org/10.3168/jds.2016-11329.

LeBlanc, S. J., K. E. Leslie, and T. F. Duffield. 2005. Metabolic predictors of displaced abomasum in dairy cattle. J. Dairy Sci. 88:159-170. https://doi.org/10.3168/jds.S0022-0302(05)72674-6.

Liboreiro, D. N., K. S. Machado, P. R. B. Silva, M. M. Maturana, T. K. Nishimura, A. P. Brandão, M. I. Endres, and R. C. Chebel. 2015. Characterization of peripartum rumination and activity of cows diagnosed with metabolic and uterine diseases. J. Dairy Sci. 98:6812-6827. https://doi.org/10.3168/jds.2014-8947.

McArt, J. A. A., D. V. Nydam, and G. R. Oetzel. 2012. Epidemiology of subclinical ketosis in early lactation dairy cattle. J. Dairy Sci. 95:5056-5066. https://doi.org/10.3168/jds.2012-5443.

Michaelis, I., O. Burfeind, and W. Heuwieser. 2014. Evaluation of oestrous detection in dairy cattle comparing an automated activity monitoring system to visual observation. Reprod. Domest. Anim. 49:621-628. https://doi.org/10.1111/rda.12337.

Nikkhah, A., C. J. Furedi, A. D. Kennedy, G. H. Crow, and J. C. Plaizier. 2008. Effects of feed delivery time on feed intake, milk production, and blood metabolites of dairy cows. J. Dairy Sci. 91:4249-4260. https://doi.org/10.3168/jds.2008-1075.

Pleticha, S., M. Drillich, and W. Heuwieser. 2009. Evaluation of the Metricheck device and the gloved hand for the diagnosis of clinical endometritis in dairy cows. J. Dairy Sci. 92:5429-5435. https://doi .org/10.3168/jds.2009-2117.

Rutten, C. J., A. G. J. Velthuis, W. Steeneveld, and H. Hogeveen. 2013. Invited review: Sensors to support health management on dairy farms. J. Dairy Sci. 96:1928-1952. https://doi.org/10.3168/ jds.2012-6107.

Schirmann, K., M. A. G. von Keyserlingk, D. M. Weary, D. M. Veira, and W. Heuwieser. 2009. Technical note: Validation of a system for monitoring rumination in dairy cows. J. Dairy Sci. 92:6052-6055. https://doi.org/10.3168/jds.2009-2361.

Schirmann, K., D. M. Weary, W. Heuwieser, N. Chapinal, R. L. A. Cerri, and M. A. G. von Keyserlingk. 2016. Short communication: Rumination and feeding behaviors differ between healthy and sick dairy cows during the transition period. J. Dairy Sci. 99:99179924. https://doi.org/10.3168/jds.2015-10548.

Schutz, M. M., and J. M. Bewley. 2009. Implications of changes in core body temperature. Pages 39-54 in Proc. Tri-State Dairy Nutr. Conf., Columbus, OH

Sheldon, I. M., G. S. Lewis, S. LeBlanc, and R. O. Gilbert. 2006. Defining postpartum uterine disease in cattle. Theriogenology 65:1516-1530. https://doi.org/10.1016/j.theriogenology.2005.08 .021 .

Simmons, K. R., A. E. Dracy, and W. O. Essler. 1965. Diurnal temperature patterns in unrestrained cows. J. Dairy Sci. 48:1490-1493. https://doi.org/10.3168/jds.S0022-0302(65)88504-6.

Soriani, N., E. Trevisi, and L. Calamari. 2012. Relationships between rumination time, metabolic conditions, and health status in dairy cows during the transition period. J. Anim. Sci. 90:4544-4554. https://doi.org/10.2527/jas.2012-5064.

Stangaferro, M. L., R. Wijma, C. Quinteros, M. Medrano, M. Masello, and J. Giordano. 2016a. Use of a rumination and activity monitoring for the identification of dairy cows with health disorders: Part II. Mastitis. J. Dairy Sci. 99:7411-7421. https://doi.org/10.3168/ jds.2016-10908.

Stangaferro, M. L., R. Wijma, C. Quinteros, M. Medrano, M. Masello, and J. Giordano. 2016b. Use of a rumination and activity monitoring for the identification of dairy cows with health disorders: Part III. Metritis. J. Dairy Sci. 99:7422-7433. https://doi.org/10.3168/ jds.2016-11352.

Stangaferro, M. L., R. Wijma, C. Quinteros, M. Medrano, M. Masello, and J. Giordano. 2016c. Use of a rumination and activity monitoring for the identification of dairy cows with health disorders: Part I. Metabolic and digestive disorders. J. Dairy Sci. 99:7395-7410 https://doi.org/10.3168/jds.2016-10907.

Steensels, M., A. Antler, C. Bahr, D. Berckmans, E. Maltz, and I. Halachmi. 2016. A decision-tree model to detect post-calving diseases based on rumination, activity, milk yield, BW and voluntary visits to the milking robot. Animal 10:1493-1500. https://doi.org/ $10.1017 / \mathrm{S} 1751731116000744$

Steensels, M., E. Maltz, C. Bahr, D. Berckmans, A. Antler, and I. Halachmi. 2017. Towards practical application of sensors for monitoring animal health: The effect of post-calving health problems on rumination duration, activity and milk yield. J. Dairy Res. 84:132-138. https://doi.org/10.1017/S0022029917000176.

Tatone, E. H., T. F. Duffield, S. J. LeBlanc, T. J. DeVries, and J. L. Gordon. 2017. Investigating the within-herd prevalence and risk factors for ketosis in dairy cattle in Ontario as diagnosed by the test-day concentration of $\beta$-hydroxybutyrate in milk. J. Dairy Sci. 100:1308-1318. https://doi.org/10.3168/jds.2016-11453.

Van Hertem, T., E. Maltz, A. Antler, C. E. B. Romanini, S. Viazzi, C. Bahr, A. Schlageter-Tello, C. Lokhorst, D. Berckmans, and I. Halachmi. 2013. Lameness detection based on multivariate continuous sensing of milk yield, rumination, and neck activity. J. Dairy Sci. 96:4286-4298. https://doi.org/10.3168/jds.2012-6188.

Wenz, J. R., D. A. Moore, and R. Kasimanickam. 2011. Factors associated with the rectal temperature of Holstein dairy cows during the first 10 days in milk. J. Dairy Sci. 94:1864-1872. https://doi.org/ 10.3168/jds.2010-3924. 